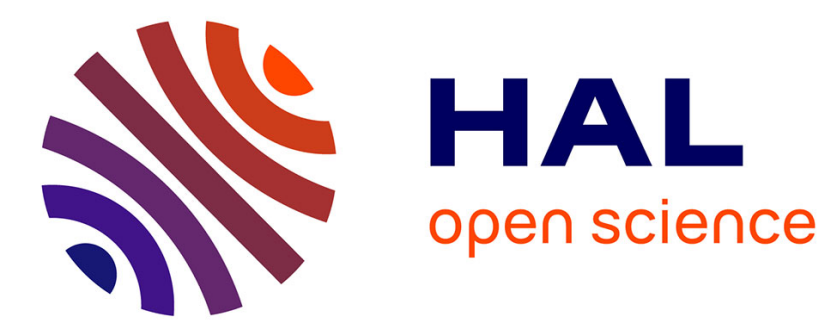

\title{
Cardioinhibitory actions of clonidine assessed by cardiac vagal motoneuron recordings.
}

\author{
Emil Toader, Andrei Cividjian, Nicolas Rentero, Robin M Mcallen, Luc
}

Quintin

\section{> To cite this version:}

Emil Toader, Andrei Cividjian, Nicolas Rentero, Robin M Mcallen, Luc Quintin. Cardioinhibitory actions of clonidine assessed by cardiac vagal motoneuron recordings.. Journal of Hypertension, 2008, 26 (6), pp.1169-80. 10.1097/HJH.0b013e3282fd10e0 . hal-00302351

\section{HAL Id: hal-00302351 https://hal.science/hal-00302351}

Submitted on 21 Jul 2008

HAL is a multi-disciplinary open access archive for the deposit and dissemination of scientific research documents, whether they are published or not. The documents may come from teaching and research institutions in France or abroad, or from public or private research centers.
L'archive ouverte pluridisciplinaire HAL, est destinée au dépôt et à la diffusion de documents scientifiques de niveau recherche, publiés ou non, émanant des établissements d'enseignement et de recherche français ou étrangers, des laboratoires publics ou privés. 
CARDIOINHIBITORY ACTIONS OF CLONIDINE ASSESSED BY CARDIAC VAGAL MOTONEURON RECORDINGS

Running head : Cardiac vagal motoneurons pattern and clonidine.

Emil Toader ${ }^{1}$, Andrei Cividjian $^{1}$, Nicolas Rentero ${ }^{1}$, Robin M McAllen ${ }^{2}$, Luc Quintin ${ }^{1}$.

Department of Physiology, CNRS UMR5123-University of Lyon $1^{1}$, France and Howard Florey Institute $^{2}$, University of Melbourne, Australia

Word count for ms : 3809 words without references.

Word count for abstract : 161 words.

Number of figures : 8 .

Acknowledgments : G Head, Melbourne, reviewed an early draft of the ms. Presented partially in Sydney, 2001. Funding : Académie de Médecine (AC), Groupe de Physiologie Appliquée and Alpha-2 Ltd studentships (AC and ET), Block grants from University of Lyon/CNRS to UMR 5123 (2000-6), "Professeur Invité" fellowship from University of Lyon (RMA; 2005-6), PICS-CNRS (LQ). Conflict of interest : none.

Correspondence : L Quintin, CNRS UMR 5123, 8 Rue R Dubois, 69622 Lyon-Villeurbanne, France, 334724328 86, quintin@univ-lyon1.fr 
Abstract

Background : Cardiac vagal activity is now considered as an important therapeutic target. However, there is a lack of direct data on how cardiac vagal motoneurons (CVM) respond to parasympathomimetic agents.

Methods : Rats were anesthetized with urethane and mechanically ventilated. Single unit activity was recorded in the nucleus ambiguus from CVM, identified by antidromic activation from the cardiac vagal branch and their barosensitivity.

Results : Nitroprusside lowered systolic blood pressure (SBP), increased heart rate (HR) and inhibited CVM activity ( $\mathrm{n}=5$ cells in 5 rats). Clonidine 1-100 $\mu \mathrm{g} . \mathrm{kg}-1$ i.v., however, lowered SBP, but increased CVM activity ( $n=8$ cells in 8 rats). It also enhanced their barosensitivity. An unsuspected further finding was that clonidine significantly increased the occurrence of CVM firing spikes separated by short (<30 ms) interspike intervals ("doublet”).

Conclusion : Such grouped patterns are known to enhance neurotransmitter release. Therefore, these data provide a new mechanism by which clonidine can further potentiate parasympathetic actions on the heart.

Key words: nitroprusside, alpha-2 agonist, clonidine, cardiac vagal motoneuron, cardiac vagal preganglionic neuron, single unit activity, firing pattern, baroreceptor-heart rate reflex, baroreflex, gain. 
INTRODUCTION

An inverse relationship exists between beat-by-beat blood pressure (BP) variability ("pressure lability") on the one hand, heart rate (HR) variability (sinus arrhythmia) and baroreceptor-heart rate reflex ("cardiac baroreflex") sensitivity [1] on the other hand. Thus cardiac vagal activity may play a key role to buffering pressure lability. Following major surgery, increased pressure lability and reduced HR variability appeared linked (figure 3B\&D in [2]). Furthermore, cardiac vagal de-activation is also an hallmark of hypertension (HBP) [3] and congestive heart failure (CHF) [4]. Following myocardial infarction, the lowered sensitivity of the cardiac baroreflex is associated with an increased incidence of sudden death [5]. Although there is no cause-effect relationship between cardiac vagal activation and successful therapy, cardiac vagal activation is considered as an index of successful treatment of cardiovascular disease [6].

While indirect measures of cardiac vagal activity such as HR or HR variability have been heavily exploited [7], direct information on the central regulation of cardiac vagal activity is scarce. Cardiac vagal motoneurons (CVM, cardiac vagal preganglionic neurons; cardiac vagal inhibitory preganglionic neurons) are located in the external formation of the nucleus ambiguus (NA) of cats and rats [8-9], where they may be recorded in vivo [10-11]. The sensitivity of the cardiac baroreflex analyzed at HR level is increased by alpha-2 agonists [12], beta-blockers, M1 antagonists (pirenzepine), converting enzyme inhibitors or angiotensin antagonists. Surprisingly, little information pertaining to the effects of drugs on cardiac vagal activity analyzed at CVM level or on vagal fibers is available [13] : this may be linked to the difficulty of recording CVM in vivo [14]. Hypotensive agents such as clonidine reduce pressure lability [2-15], simultaneously generate a large sinus arrhythmia and increase the sensitivity of the cardiac baroreflex in hypertensive patients recovering from major surgery [2].

Given the a) clinical utility of alpha-2 agonists in recruiting cardiac vagal activity and reducing pressure lability [16] b) renewed interest in the use of centrally acting agents [17-18] c) increased cardiac vagal activity observed experimentally following clonidine [19-24], and because the opposite effects of a peripherally acting vasodilator, nitroprusside (SNP) and clonidine on baroreflex function, CVM neurons were hypothesized to be activated by clonidine and inhibited by SNP. Unexpectedly, upon data analysis, the firing pattern of CVM appeared altered following clonidine and thus was analyzed. 


\section{MATERIALS AND METHODS}

Anesthesia : Experiments approved by the Rhône-Alpes Committee for the care of Animals were performed on Sprague-Dawley male rats (Harlan, Gannat, France, 325-400g). Methods were as described [11]. Isoflurane anesthesia was switched over to urethane 1.4 g.kg-1 i.v. over 15-30 min before recording. During recordings, the animal was paralyzed (metocurine iodide $0.2 \mathrm{mg}$ i.v., Metubine ${ }^{\circledR}$, Lilly, Indianapolis, IN). This was done once anesthesia had been established to abolish withdrawal reflex. Paralysis was allowed to wear off between doses to ensure adequate anesthesia. If necessary, urethane (10-20\% of original dose) was given i.v. before re-establishing paralysis. After tracheotomy, rats were mechanically ventilated ( $f \sim 72 / \mathrm{min} ; \sim 40 \% \mathrm{O}_{2} /$ air; end-tidal $\mathrm{CO}_{2} \sim 25-30$ and 30-35 mmHg during surgery and recording respectively; Engström Elisa Duo, Gambro Engström, Bromma, Sweden). The rectal temperature was kept at $\sim 37.5^{\circ} \mathrm{C}$ (Harvard, Edenbridge, Kentucky). The bladder was canulated and drained. The right femoral vein was catheterized. A percutaneous transluminal coronary angioplasty catheter with an inflatable balloon at its tip (PTCA catheter 2-3mm, Boston Scientific, Galway, Ireland) was introduced through the right femoral artery up to the thoracic level, to monitor BP and generate pressure rises [25] ("balloon inflation"). A slow infusion ( $<3 \mathrm{ml} / \mathrm{h}$ ) through the arterial lumen of the PTCA catheter prevented hypovolemia [26] and clotting. A 3 lead electrocardiogram (EKG) was set up.

Surgery : The right thoracic vagus was exposed through a thoracotomy (2nd right intercostal space). The craniovagal cardiac branch ("branch") was identified by its ability to cause bradycardia when stimulated electrically $(20-50 \mathrm{~Hz}, 2-7 \mathrm{~V}, 0.05 \mathrm{~ms})$ [11]. A small sheet of polyethylene was inserted beneath the branch to insulate it. A pair of electrodes (teflon-coated silver wire bared at the tips, 125 $\mu \mathrm{m})$ was placed under the branch and secured in contact with silicon gel (Wacker, Munich, Germany). The wires were secured to avoid pulling on the nerve. The viability of the branch was then rechecked by stimulating through the implanted electrodes. The experiment was discontinued if this failed to cause bradycardia. The rat was fixed in a stereotaxic frame, with the head ventroflexed sufficiently to bring the surface of the medulla horizontal. The tail was pulled to stabilize the medulla. The medulla was exposed by removing part of the occipital bone with rongeurs. The dura and the atlantooccipital membrane were reflected. 
Single unit recording : Carbon fiber electrodes were made [27] with the fiber to protrude 10-15 $\mu \mathrm{m}$ beyond the micropipette. Electrical contact was made by a chlorided silver wire with $2 \mathrm{M} \mathrm{NaCl}$ in the pipette shaft. Electrodes were lowered vertically through the dorsal surface of the medulla (1.5-2.2 $\mathrm{mm}$ to the right of the calamus scriptorius; depth=1.5-2 $\mathrm{mm}$ corresponding to the external formation of the NA). Unit activity was recorded differentially between the carbon fiber electrode and a reference silver wire placed on the medullary surface using a preamplifier (Grass P16, Quincy, MA). The signal was amplified $(x 10,000)$ and band-pass filtered $(300-3000 \mathrm{~Hz})$ before display on an oscilloscope (Tektronix 5111A, Beaverton, OR). The unit signal was digitized at $18.5 \mathrm{kHz}$ (Instrutech, New York, NY) then recorded (JVC, Friedberg, Germany) along with BP, EKG, CO2 (digitized at $4.5 \mathrm{kHz}$ ), stimulus, vocal messages and event markers. Signals were also recorded with a computer-based system ("Micro 1401"; Spike2 software, CED, Cambridge, U.K), for which the CVM signal was digitized at $15 \mathrm{kHz}$. On-line spike discrimination was performed with a time amplitude window discriminator (FHC, Brunswick, ME). CVM were sought by their fixed-latency response to stimulation of the branch (0.5-5 mA, $0.05 \mathrm{~ms}, \sim 1 \mathrm{~Hz}$ [11]). Signal averaging software (Spike2 v3.21, C.E.D., Cambridge, U.K) helped to localize CVM. Once a unit recording had been isolated (figure 1A), it was subjected to time-controlled collision testing (figure 1B) [11-28]. Unit discrimination and collision tests were re-checked and edited off-line from the recorded signals.

Nitroprusside : bolus doses of nitroprusside ( $2 \mu \mathrm{g}$, sodium nitroprusside dihydrate in saline, $25 \mu \mathrm{g} / \mathrm{ml}$, Fluka, Buchs, Switzerland) were administered i.v. In some experiments, phenylephrine $(2 \mu \mathrm{g}, 25$ $\mu \mathrm{g} / \mathrm{ml}$, Boehringer, Ingelheim, Germany) was then injected at the pressure nadir to cause a rising pressure ramp (figure 3 ).

Clonidine : clonidine (5 or $50 \mu \mathrm{g} / \mathrm{ml}$ in saline, Sigma, St Louis, MO) was infused in $1,3,10,30,100$ $\mu \mathrm{g} / \mathrm{kg}$ i.v. cumulative doses, over $\sim 10 \mathrm{~min}$. Two or three BP rises of $\leq 30-50 \mathrm{mmHg}$ [29] were generated by balloon inflation after each clonidine dose. At least 2-minute intervals were allowed between inflations for full recovery of $\mathrm{BP}$ and $\mathrm{HR}$ to baseline values. CVM and $\mathrm{HR}$ responses were measured over 1s windows. Once the pharmacological experiment was completed, the animal was killed with an overdose of chloral hydrate (200 mg i.v.).

Firing Pattern : Barosynchronicity (cardiac rhythmicity, pulse-locked character) of neurons was tested online, by generating pulse-triggered correlation histograms of single unit activity in $5 \mathrm{~ms}$ bins, using 
Spike2 (figure 1C). The stored BP and EKG signals were converted back from Instrutech to analog signals, then redigitized at 1 and $4 \mathrm{kHz}$ respectively (Keithley KPCMCIA 16AIAO, Cleveland, $\mathrm{OH}$ ). Systolic BP (SBP)-RR interval and SBP-CVM relationships were generated with custom-made software $\left(\mathrm{RECAN}^{\odot}\right.$, Alpha-2 Ltd, Lyon, France). Discriminated spikes were imported in RECAN from Spike2 files and converted to firing rate integrated over 1 s window (e.g. figure $2 \mathrm{~A}$ ). The data were analyzed in 2 ways (see Results): a) counting every spike as a single event; b) counting double spikes occurring within $30 \mathrm{~ms}$ as a single event. Interspike interval histograms of single unit activity were also generated, using $10 \mathrm{~ms}$ bins. The 100 s periods used for interspike-interval analysis were divided in 5s-window intervals. Spikes and double spikes were averaged over $5 \mathrm{~s}$ windows. Double spikes ("doublet") were counted on these intervals and plotted against the mean firing rate obtained on same periods. Triple spikes ("triplet") were considered as 2 double spikes. Slopes were averaged over baseline and clonidine $100 \mu \mathrm{g} \cdot \mathrm{kg}^{-1}$ periods respectively.

Nitroprusside : total CVM spike counts were measured for 50 s before (baseline) and 50 s immediately after the injection (response; figure 2B). To analyze the baroreflex during nitroprusside-phenylephrine sequences, CVM firing rate was averaged over 6 respiratory cycles and plotted against SBP. Linear regression lines were calculated for selected segments of the BP trace, handling separately the sections where pressures were below and above baseline levels.

Cardiac baroreflex measured at the CVM : In order to study the SBP-CVM relationship, SBP and CVM activity were averaged over 3 respiratory cycles ( $2.5 \mathrm{~s})$, to avoid confounding effects of respiratory modulation [11]. Data were taken from the full pressure sequence due to balloon inflation, including the transient hypotension following deflation, ending when BP returned to baseline. Linear regression lines were calculated separately for sections above and below resting BP. The appropriate reflex delay to allow for was calculated as the number of heart beats, which maximized the correlation coefficient ( $r$ ) between the two signals (averaged SBP and CVM firing rate). Cases where $r$ was $<0.7$ were discarded. Duplicate measurements were averaged.

Cardiac baroreflex analyzed at the heart: SBP and R-R interval signals were filtered at $0.8 \mathrm{~Hz}$ and $0.3 \mathrm{~Hz}$ respectively using a 201 -coefficients low-pass finite impulse response filter. Only the first $5 \mathrm{~s}$ of the balloon-induced pressure rise were used to calculate the slope of the SBP-RR relationship (cardiac baroreflex analyzed at the heart), to measure selectively the parasympathetic component of the 
reflex : indeed the slower, sympathetic, mechanism contributes only after $5 \mathrm{~s}$ [30]. In this case, the appropriate reflex delay to apply was computed by measuring the number of heart beats between the mid-heights of the SBP and R-R interval rises. Linear regression was then applied to calculate the SBP-RR interval slope.

Statistical analysis : Data are expressed as mean \pm SD in text and \pm SEM in figures. SBP, RR, SBPCVM slope and SBP-RR interval slope data were analyzed using one-way repeated measures ANOVA (STATISTICA 5.1, Statsoft, Tulsa, OK), after verifying visually the normal distribution using log-normal plots. If ANOVA suggested significance, the LSD test post-hoc was used. The firing rate, the normalized firing rate, and the SD of SBP and RR intervals did not present normal distributions. Therefore non-parametric Friedman analysis, followed by Wilcoxon paired test were used, if appropriate. $p<0.05$ was chosen as significant. 
Sixteen units which met the criteria for CVM units [10-11] were recorded in 39 rats (table 1 and figure 1). However, given the complexity of the experiments, all parameters (HR, BP, unit activity) could not be collected in all instances (details in table 1). Thus, 13 units were selected for detailed study: 5 were tested with nitroprusside and 8 were used for clonidine studies.

A peripheral vasodilator, nitroprusside, led to brief hypotension (SBP: $128.4 \pm 4.0$ to $81.6 \pm 13.7$ $\mathrm{mmHg})$, increase in HR $(387.5 \pm 7.8$ to $392.3 \pm 11.7 \mathrm{bpm}, \mathrm{n}=5)$ and inhibited all 5 CVM units (figure 2). Vehicle did not modify pressure, HR or CVM activity $(n=5)$. When nitroprusside was followed by phenylephrine administered immediately after the nadir in pressure, a clear relationship linked CVM unit activity to the level of pressure (figure 3A). However, the slope of the CVM-SBP relation was greater at pressures above resting levels than below (figure 3B), indicating non-linearity.

A centrally acting vasodilator, clonidine, led to decreased pressure (SBP : 145.5 \pm 16.6 to $122.6 \pm 15.6$ $\mathrm{mmHg}, \mathrm{p}<0.05), \mathrm{HR}(371.8 \pm 25.7$ to $350.7 \pm 26.2 \mathrm{bpm}, \mathrm{ns}, \mathrm{n}=8$ rats) and increased CVM activity ( $\mathrm{n}=8$ cells, $p<0.05$, figure $4 A$ ). Vehicle did not modify pressure, HR or CVM activity ( $n=8$ cells). When one silent CVM was encountered, clonidine activated it (figure 4B). Clonidine also led to a change in CVM activity pattern (figure 5A): the single CVM action potentials under baseline conditions were often replaced by high frequency double or triple spikes following clonidine (figures 5,6 ) in 5 out of 8 cells, presenting with the highest baseline firing rate, especially when the incidence of doublets is normalized for pressure (figure 5C). When CVM interspike intervals were grouped into four ranges (divisions: $30,600,1300 \mathrm{~ms}$, figure $5 \mathrm{~B}$ ), clonidine clearly increased the numbers of short intervals, especially those $<30 \mathrm{~ms}$, at the expense of long intervals ( $n=5$ cells; figures $5 B-D)$. Even if double spikes were counted as single events, the firing rate remained significantly elevated after clonidine 100 ug.kg-1 (8.62 Hz vs. baseline : $5.28 \mathrm{~Hz}$ when all spikes were counted; $7.19 \mathrm{~Hz}$ vs. baseline : $5.08 \mathrm{~Hz}$ when double spikes were counted as single events; $p=0.04$ in both cases). Finally, double spikes firing pattern was observed as more prominent during pressure rises than during resting conditions (figures 5E-F) following clonidine $100 \mu \mathrm{g} . \mathrm{kg}-1$.

Cumulative doses of clonidine (1-100 $\mu$ g.kg-1 i.v.) decreased SBP and HR (see above), while increasing sinus arrhythmia (figure 6) and CVM firing rate in a dose-dependent manner (figures 8A-E; 
$\mathrm{n}=8$ cells for unit activity, SBP and RR interval). Vehicle and the lowest clonidine doses ( 1 and 3 $\mu g . k g-1)$ caused no significant effect (data not shown). The slope of the SBP-CVM activity relationship (cardiac baroreflex analyzed at CVM level, $n=8$ cells, figures $7 C-D$ and $8 F$ ) was significantly enhanced at clonidine $100 \mu \mathrm{g} . \mathrm{kg}-1$ compared with baseline $(p=0.043)$, but the SBP-RR interval relationship not significantly so (cardiac baroreflex analyzed at heart level, $n=8$ rats, figure $8 G, p=0.66$ ). 
DISCUSSION

Peripherally- and centrally-acting vasodilators exerted contrasting effects on CVM activity. The centrally acting agent, clonidine, increased CVM activity and modified CVM firing pattern from single spike firing to double or triple spikes volleys of action potentials. Lastly, the slope of the cardiac baroreflex analyzed at CVM level was increased.

\section{METHODOLOGY}

Criteria for identification of CVM units [10-11] were met. A pressure-unit relationship (cardiac baroreflex relationship analyzed at CVM level) allowed to relate this pressure-unit relationship to the pressure-RR relationship [31] (cardiac baroreflex analyzed at the heart level). Care was taken to increase pressure by $<30-50 \mathrm{~mm} \mathrm{Hg}$ to avoid stimulating ventricular mechanoreceptors [29] and loosing the unit. The present analysis follows an analysis performed with respect to the sympathetic vasomotor baroreflex : sympathetic premotoneurons and lumbar sympathetic discharge exhibit an identical relationship to BP (figure 9-3 in [32]). These [32] and present data demonstrate tight coupling between brain stem cardiovascular cells and their parasympathetic and sympathetic effectors, cardiac or vascular, for both divisions of the autonomic nervous system.

Urethane suppresses the bradycardia evoked by clonidine [33] and is associated with a high parasympathetic activity [34]. Thus low dose clonidine (1-3 $\mu \mathrm{g} \cdot \mathrm{kg}-1)$ elicited little increase in CVM activity, against an already existing high baseline activity. Accordingly, low dose clonidine failed to increase aortic depressor nerve discharge in chloralose-urethane anesthetized rabbits [22]. Despite this drawback, urethane was used, as isoflurane silences CVM activity (Cividjian, unpublished observations).

Lastly, CVM are under important respiratory influences detailed elsewhere [10-11]. Given the complexity of the experiments, the phrenic nerve was not recorded. Thus no analysis on how clonidine may alter the respiratory input to CVM was attempted. 
FINDINGS

No attempt has been made so far to record CVM during decreases in pressure. When the baroreflex is challenged with nitroprusside, hypotension and increase in HR are accompanied by an inhibition of the CVM (figure 2). One interesting finding is the fact that hypotension does not always entirely suppresses CVM firing (figure 2C) and raise the question of a possible baro-independent component of CVM activity. This cardiac vagal de-activation (figure 2) appears reciprocal to the sympathetic activation observed during nitroprusside-induced hypotension [35]. The pressure-unit relationship slopes do not appear linear when responses to nitroprusside and phenylephrine are considered (figure 3B), as in humans [36].

By contrast to nitroprusside, clonidine induced hypotension and bradycardia and an activation of CVM. Thus, these drugs present opposite effects on the sympathetic and parasympathetic efferent limbs of the baroreflex. Second, the effect of clonidine on the sympathetic baroreflex is ascribed to at least a dual site of action : rostral ventrolateral medulla [35] and intermediolateral cell column [37]. By contrast, the effect of clonidine on the cardiac baroreflex arc is less delineated. The activation of CVM appears in line with the parasympathetic activation described with centrally acting agents : a) the bradycardia evoked by clonidine is observed even after beta-blockade [23]. This bradycardia is suppressed by vagotomy [23] b) clonidine enhances the bradycardia evoked by pressure rise following pre-treatment with guanethidine, reserpine and beta-blockers [19] [20] c) clonidine increases the discharge of the primary afferent baroreceptor neurons (first-order neurons) [21]. Thus, clonidine may act at two or more levels within the cardiac baroreflex arc : primary afferent baroreceptors neurons [21-22] and centrally, at or before CVM (present data). A site of action in the nucleus tractus solitarius appears unlikely [21], however. Third, clonidine may activate previously silent units ( $n=1$, figure 4B). Thus, one mechanism leading to increased sensitivity of the cardiac baroreflex may be recruitment of the pool of active CVM : this has to be documented. Fourth, the most unexpected finding was the change in CVM firing pattern : single spikes were seen at baseline, in contrast to high frequency volleys of action potentials after clonidine (figures 5 and 6). This effect of clonidine is even more prominent during pressure rises, as opposed to resting pressure (figure 5E). This last observation is in line with a previous hypothesis on baroreflex assessment [38] : the "sequence" technique observes spontaneous pressure changes around resting pressure and reveals a lower slope of the cardiac baroreflex as opposed to the slope measured after phenylephrine challenge. Here, balloon inflation leads to 
large pressure changes (figure $5 \mathrm{E}$ and 7 ), even if care is taken to avoid stimulation of high pressure intraventricular mechanoceptors. The present data suggest that the difference in slope measured by the sequence technique opposed to the drug-induced technique [38] may be a consequence of recruitment of CVM or changed firing pattern or both. Fifth, the shift in CVM firing patterns to include frequent doublets, especially in cells with high resting activity, prompts the following questions: a) are frequent doublet spikes the natural accompaniment of high activity in CVM; or b) does the higher prevalence of doublets after clonidine indicate a direct effect of clonidine on CVM ? The analysis illustrated in figure $5 \mathrm{c}, \mathrm{d}$ found that the relation between the incidence of doublets and mean firing rate is altered by clonidine, strongly supporting the latter view. Sixth, could these volleys of action potential increase acetylcholine (Ach) release at the level of the sinus node ? This may indeed be the case [39-40]. It is established that grouped, high frequency stimulation patterns are more effective than tonic patterns at releasing neurotransmitters [41-42]. Furthermore, "larger concentrations of [Ach] seem to produce a more than proportional inhibitory lengthening" of the RR interval [43]. These factors could all enhance the effectiveness of cardiac slowing following clonidine. The recruitment of CVM and their doublet or triplet firing following clonidine may also underlie the increase in beat-bybeat sinus arrhythmia under resting conditions (figure 6). Finally, the observation of a changed pattern of firing strongly supports the study of CVM at single unit level as the tool to delineate the intrinsic relationship between cardiac vagal activity and sinus arrhythmia, during pharmacological or physiological manipulation, as opposed to observation of plain HR or of vagal recording.

However, the demonstration of a definite link between changed CVM firing pattern and improved pressure lability would be difficult : pressure lability is almost non-existent in anesthetized rats. Could this be applied to conscious hypertensive humans ? After clonidine, as each increase in pulse pressure is followed by a volley of action potential, and possibly larger acetylcholine release, any minor increase in vasomotor sympathetic activity and corresponding surge in pressure is followed within the same beat [44] by a larger reduction in instantaneous HR, as opposed to preceding instantaneous $\mathrm{HR}$. This is compatible with the observation that BP lability is almost totally suppressed while HR variability is largely enhanced in hypertensive humans recovering from major surgery and treated with clonidine (compare respective BP and HR traces in figures 3B vs. 3D in [2]).

Finally, the recruitment of silent unit (figure 4) and the changes in firing patterns (figure 5) may be brought together with an increased slope of the SBP-CVM activity relationship (figure 8F) : activity in- 
creases while pressure decreases, suggestive of a resetting and of increased sensitivity of the central limb of the cardiac baroreflex. Such an increased sensitivity of the integrative mechanism fits with the increase in SBP-RR relationship, previously repeatedly demonstrated [12-22-24].

Can this pharmacological increase in cardiac baroreflex sensitivity be related to similar phenomenon under physiological condition [45] ? An excitatory amino-acid, DL homocysteic acid, micro-ejected in the ventrolateral periaqueductal grey matter (PAGvl), enhances the bradycardia evoked by stimulation of the aortic depressor nerve [46]. Thus, the pharmacological stimulus, clonidine, may mimic the physiological condition, PAGvl stimulation, in sensitizing the central limb of the cardiac baroreflex [46].

\section{PERSPECTIVES}

Firstly, the cardiac vagal activity is viewed as a key target to manipulate the cardiovascular system [6]. If an increased routine for CVM recording leads to higher success rate, the present model will allow pharmacological investigation. For example, B-natriuretic peptide increases CVM activity during von Bezold-Jarisch reflex [47]. Also, some drugs increase the slope of the cardiac baroreflex (see introduction). Because of the therapeutic importance of the cardiac vagal activity [6], these drugs would benefit from an analysis of the cardiac baroreflex at CVM level : this model should bring molecules to activate the cardiac vagal activity without side effects. Secondly, the change in firing pattern and increased slope observed here may be related to reduced pressure lability [2] (see above). Outcome is linked to beat-by-beat pressure lability, independently from the mean level of pressure [48-51] : would reduced lability following alpha-2 agonist be linked to improved outcome in hypertensive patients ? Thirdly, low HR variability and low baroreflex sensitivity are also associated with poor outcome following myocardial infarction [5]. Some CVM present dromotropic [52] and possibly bathmotropic properties. However, they have not yet been electrophysiologically identified. Given the therapeutic importance of cardiac vagal activity in relationship to arrhythmia, this matter should be deciphered. Lastly, the present findings may be of interest as cardiac vagal activity is defective in $\mathrm{CHF}$ [4] and as clonidine improves symptoms of CHF [17]. This matter is of importance as clonidine is no longer widely used in the cardiology setting for the treatment of $\mathrm{HBP}$ and $\mathrm{CHF}$, at variance with its use in the anesthesia/critical care setting. Thus examining the effects of newer centrally acting agents (ril- 
melidine, monoxidine) on CVM and pressure lability may strengthen the rationale for impacting centrally the cardiovascular system in HBP and CHF.

Peripherally- and centrally-acting hypotensive agents respectively inhibit and activate cardiac vagal motoneurons. Clonidine changes the firing pattern of cardiac vagal motoneurons toward volleys of action potentials. Finally, the sensitivity of the central limb of the cardiac baroreflex is increased. Given the sympatholytic and parasympathomimetic effect of alpha-2 agonists, these properties may explain the reduced pressure lability observed in HBP following centrally-acting agents. 
1. Mancia G, Ferrari A, Gregorini L, Parati G, Pomidossi G, Bertinieri G et al. Blood pressure variability in man : its relation to high blood pressure, age and baroreflex sensitivity. Clin.Sci. 1980; 59: 401s-404s.

2. Parlow J, Begou G, Sagnard P, Cottet-Emard JM, Levron JC, Annat G et al. Cardiac baroreflex during the postoperative period in patients with hypertension : effect of clonidine. Anesthesiology 1999; 90: 681-692.

3. Julius S, Pascual AV, London R. Role of parasympathetic inhibition in the hyperkinetic type of borderline hypertension. Circulation 1971; 44: 413-418.

4. Eckberg DL, Drabinsky M, Braunwald E. Defective cardiac parasympathetic control in patients with heart disease. N.Engl.J.Med. 1971; 285: 877-883.

5. La Rovere MT, Bigger JT, Marcus FI, Mortara A, Schwartz PJ. Baroreflex sensitivity and heart rate variability in prediction of total cardiac mortality after myocardial infarction. Lancet 1998; 351: 478-484.

6. Townend JN Littler WA. Cardiac vagal activity : a target for intervention in heart disease. Lancet 1995; 1: 937-938.

7. Bigger JT \& Schwartz PJ. Markers of vagal activity and the prediction of cardiac death after myocardial infarction. In: Levy MN, Schwartz PJ (editors). Vagal control of the heart : experimental basis and clinical implications. Armonk: Futura; 1994. pp. 481-508.

8. Hopkins DA, Bieger D, deVente J, Steinbusch WM. Vagal efferent projections : viscerotopy, neurochemistry and effect of vagotomy. Progress in Brain Research 1996; 107: 79-96.

9. Nosaka S, Yamamoto T, Yasunaga K. Localization of vagal cardioinhibitory preganglionic neurons within rat brain stem. J Comp Neur 1979; 186: 79-92.

10. McAllen RM Spyer KM. The baroreceptor input to cardiac vagal motoneurones. J.Physiol.(London) 1978; 282: 365374.

11. Rentero N, Cividjian A, Trevaks D, Pequignot JM, Quintin L, McAllen RM. Activity patterns of cardiac vagal motoneurons in rat nucleus ambiguus. Am.J.Physiol. 2002; 283: R1327-R1334.

12. Sleight $\mathrm{P}$, West MJ, Korner PI, Oliver JR, Chalmers JP, Robinson JL. The action of clonidine on the baroreflex control of heart rate in conscious animals and man and on single aortic baroreceptor discharge in the rabbit. Archives of International Pharmacodynamy and Therapeutics 1975; 214: 4-11.

13. Gilbey MP, Jordan D, Richter DW, Spyer KM. Synaptic mechanisms involved in the inspiratory modulation of vagal cardio-inhibitory neurones in the cat. J.Physiol.(London) 1984; 356: 65-78.

14. Mendelowitz D. Advances in parasympathetic control of heart rate and cardiac function. NIPS 1999; 14: 155-161.

15. Girard A, Fevrier B, Elghozi J-L. Cardiovascular variability after rilmelidine challenge : assessment of acute dosing effects by mean of spectral analysis. Fundamental and Clinical Pharmacology 1995; 9: 366-371.

16. Parati G, Di Rienzo M, Ulian L, Santucciu C, Girard A, Elghozi J-L et al. Clinical relevance of blood pressure variability. J.Hypertension 1998; 16: S25-S33.

17. Manolis AJ, Olympios C, Sifaki M, Handanis S, Bresnahan M, Gavras I et al. Suppressing sympathetic activation in congestive heart failure : a new therapeutic strategy. Hypertension 1995; 26: 719-724.

18. Tank J, Diedrich A, Szczech E, Luft FC, Jordan J. Alpha-2 adrnergic transmission and human baroreflex regulation. 43 2004; 1035-1041.

19. Kobinger W Walland A. Evidence for a central activation of a vagal cardiodepressor reflex by clonidine. Eur.J.Pharmacol. 1972; 19: 203-209.

20. Kobinger W Walland $A$. Modulating effect of central adrenergic neurons on a vagally mediated cardioinhibitory reflex. Eur.J.Pharmacol. 1973; 22: 344-350.

21. Laubie $M$, Schmitt $H$, Drouillat $M$. Action of clonidine on the baroreceptor pathway and medullary sites mediating vagal bradycardia. Eur.J.Pharmacol. 1976; 38: 293-303.

22. Korner PI, Oliver JR, Sleight $\mathrm{P}$, Chalmers JP, Robinson JS. Effect of clonidine on the baroreceptor-heart rate reflex and on single aortic baroreceptor fibre discharge. Eur.J.Pharmacol. 1974; 28: 189-198.

23. Robson RD Kaplan HR. An involvement of ST155 [2-(2,6-dichlorophenylamino)-2-imidazoline hydrochloride, Catapress R) in cholinergic mechanisms. Eur.J.Pharmacol. 1969; 5: 328-337. 
24. Tank J, Jordan J, Diedrich A, Obst M, Plehm R, Luft FC et al. Clonidine improves spontaneous baroreflex sensitivity in conscious mice through parasymapthetic activation. Hypertension 2004; 43: 1042-1047.

25. Cividjian A, Rentero N, McAllen RM, Quintin L. A simple method for generating a blood pressure-unit activity relationship for central cardiovascular neurons in the rat. Experimental Physiology 2002; 87: 535-538.

26. Quintin L, Gillon JY, Saunier CF, Chouvet G, Ghignone M. Continuous volume infusion improves circulatory stability in anesthetized rats. J.Neurosci. Methods. 1989; 30: 77-83.

27. Kuras A Gutmaniene N. Preparation of carbon-fibre microelectrode for extracellular recording of synaptic potentials. J.Neurosci.Methods. 1995; 62: 207-212.

28. Lipski J. Antidromic activation of neurones as an analytical tool in the study of the central nervous system. J.Neurosci.Methods. 1981; 4: 1-32.

29. Faris I, lannos J, Jamieson G, Ludbrook J. Comparison of methods for eliciting the baroreceptor-heart rate reflex in conscious rabbits. Clin Exp Pharmacol Physiol 1980; 7: 281-291.

30. Coleman TG. Arterial baroreflex control of heart rate in the conscious rat. Am.J.Physiol. 1980; 238: H515-H520.

31. Smyth HS, Sleight P, Pickering GW. Reflex regulation of arterial pressure during sleep in man. Circ.Res. 1969; 24: 109-121.

32. Guyenet P. Role of the ventral medulla oblongata in blood pressure regulation. In: Loewy AD, Spyer KM (editors). Central Regulation of Autonomic Functions. Oxford: Oxford University Press; 1990. pp. 145-167.

33. Armstrong JM, Lefevre-Borg F, Scatton B, Cavero I. Urethane inhibits cardiovascular responses mediated by the stimulation of alpha-2 adrenoceptors in the rat. J Pharmacol Exp Ther 1982; 223: 524-535.

34. Katona PG, Lipson D, Dauchot PJ. Opposing central and peripheral effects of atropine on parasympathetic cardiac control. Am.J.Physiol. 1977; 232: H146-H151.

35. Sun MK Guyenet P. Effect of clonidine and gamma-aminobutyric acid on the discharges of medullo-spinal sympathoexcitatory neurons in the rat. Brain Res. 1986; 368: 1-17.

36. Pickering TG, Gribbin B, Sleight $P$. Comparison of the reflex heart rate response to rising and falling arterial pressure in man. Cardiovasc.Res. 1972; 6: 277-283.

37. Guyenet P Cabot JB. Inhibition of sympathetic preganglionnic neurons by catecholamines and clonidine : mediation by an alpha-adrenergic receptor. J.Neurosci. 1981; 1: 908-917.

38. Parlow J, Viale JP, Annat G, Hughson RL, Quintin L. Spontaneous cardiac baroreflex in humans : comparison with drug-induced responses. Hypertension 1995; 25: 1058-1068.

39. Levy MN, lano T, Zieske H. Effects of repetitive bursts of vagal activity on heart rate. Circ.Res. 1972; 30: 186-195.

40. Dexter F, Yang T, Levy MN. Analysis of vagally induced sinus arrhythmia. J Theor Biol 1992; 159: 507-511.

41. Gonon F. Non-linear relationship between impulse flow and dopamine released by rat midbrain dopaminergic neurons as studied by in vivo electrochemistry. Neuroscience 1988; $24: 19-28$.

42. Pernow J, Schwieler J, Kahan T, Hjemdahl P, Oberle J, Wallin BG et al. Influence of sympathetic discharge pattern on norepinephrine and neuropeptide Y release. Am.J.Physiol. 1989; 257: H866-H872.

43. Brown GL Eccles JC. The action of a single vagal volley on the rhythm of the heart beat. J.Physiol.(London) 1934; 82: 211-241.

44. DeBoer RW, Karemaker JM, Strackee J. Hemodynamic fluctuations and baroreflex sensitivity in humans: a beat-tobeat model. Am.J.Physiol. 1987; 253: H680-H689.

45. Hilton SM Spyer KM. Participation of the anterior hypothalamus in the baroreceptor reflex. J.Physiol.(London) 1971; 218: 271-293.

46. Inui K, Murase S, Nosaka S. Facilitation of the arterial baroreflex by the ventrolateral part of the midbrain periaqueductal grey matter in rats. J.Physiol.(Lond) 1994; 477: 89-101.

47. Toader E, McAllen RM, Cividjian A, Woods RL, Quintin L. Effect of systemic B-type natriuretic peptide on cardiac vagal motoneuron activity. Am.J.Physiol. 2007; 293: H3465-H3470.

48. Parati G, Pomidossi G, Albini F, Malaspina D, Mancia G. Relationship of 24-hour blood pressure mean and variability to severity of target-organ damage in hypertension. J.Hypertension 1987; 5: 93-98. 
49. Kikuya M, Hozawa A, Ohokubo T, Tsuji I, Michimata M, Matsubara M et al. Prognostic significance of blood pressure and heart rate variabilities : the Ohasama study. Hypertension 2000; 36: 901-906.

50. Sander D, Kukla C, Klingelhofer J, Winbeck K, Conrad B. Relationship between circadian blood pressure patterns and progression of early carotid artherosclerosis : a 3 year follow up study. Circulation 2000; 102: 1536-1541.

51. Aronson S, Fontes ML, Miao Y, Mangano DT. Risk index for perioperative renal dysfunction/failure : critical dependence on pulse pressure hypertension. Circulation 2007; 115: 733-742.

52. Massari VJ, Johnson TA, Gatti PJ. Cardiotopic organization of the nucleus ambiguus ? an anatomical and physiological analysis of neurons regulating atrioventricular conduction. Brain Res 1995; 679: 227-240. 


\begin{tabular}{|c|c|c|c|c|c|c|c|}
\hline Neurone & Protocol & $\begin{array}{l}\text { Data in- } \\
\text { clusion }\end{array}$ & $\begin{array}{l}\text { Latency } \\
\text { (ms) }\end{array}$ & $\begin{array}{l}\text { Refractory } \\
\text { period } \\
\text { (ms) }\end{array}$ & $\begin{array}{l}\text { Collision } \\
\text { time } \\
\text { (ms) }\end{array}$ & $\begin{array}{c}\text { Firing rate } \\
\text { (spikes/s : } \\
\mathrm{Hz} \text { ) }\end{array}$ & $\begin{array}{l}\text { Conduction } \\
\text { velocity } \\
(\mathrm{m} / \mathrm{s})\end{array}$ \\
\hline $\mathrm{N} 1$ & CLO & $* * * *$ & 6.78 & 3.2 & 7.36 & 1.83 & 10.32 \\
\hline N2 & CLO & * & 5.26 & 2.6 & 6.54 & 3 & 13.31 \\
\hline N3 & CLO & $* * *$ & & & & & \\
\hline N4 & CLO & $* *$ & 7.56 & 5.8 & 8.42 & 7.5 & 9.26 \\
\hline N5 & CLO & ** & 10.91 & 2 & 12.35 & 9.7 & 6.42 \\
\hline N6 & CLO & * & 5.03 & 3.94 & 5.85 & 6.5 & 13.92 \\
\hline N7 & $\mathrm{CLO}$ & $* * *$ & 10.02 & 3 & 10.36 & 7.5 & 6.99 \\
\hline N8 & CLO & $* *$ & 5.51 & 5 & 6.7 & 0 & 12.7 \\
\hline N9 & $\mathrm{CLO}$ & $* * *$ & & & & & \\
\hline N10 & CLO & $* * * *$ & 6.71 & 1.5 & 7.5 & 1 & 10.43 \\
\hline N11 & NPS & ** & 5.66 & 1.54 & 6.43 & 0.01 & 12.37 \\
\hline $\mathrm{N} 12$ & NPS & $* *$ & 7.52 & 1.76 & 8.71 & 1 & 9.31 \\
\hline $\mathrm{N} 13$ & NPS & $* *$ & 8.63 & 3 & 9.7 & 4.5 & 8.11 \\
\hline N14 & NPS & $* *$ & 8.55 & 4.4 & 12.2 & 0.15 & 8.19 \\
\hline N15 & NPS & $* *$ & 7.66 & 3.17 & 9.78 & 1 & 9.14 \\
\hline N16 & CLO & $* * * *$ & 8.18 & 3 & 10.8 & 0.4 & 8.56 \\
\hline N17 & CLO & ** & 12.21 & 4 & 14 & 1.3 & 5.73 \\
\hline N18 & CLO & $* *$ & 5.51 & 1.9 & 6.22 & 0.1 & 12.70 \\
\hline \multicolumn{3}{|c|}{ Mean } & 7.7 & 3.1 & 9.0 & 2.9 & 9.8 \\
\hline \multicolumn{3}{|c|}{ SD } & 2.2 & 1.3 & 2.5 & 3.3 & 2.6 \\
\hline
\end{tabular}

Table1: CVM characteristics. Data were obtained in different animals. Latency is measured between the stimulation artefact and the generated action potential. * indicates CVM not included in presentation (see results); ${ }^{* *}$ : CVM, HR and SBP data included in analysis; ${ }^{* *}:$ HR and SBP data included in analysis; ${ }^{* * * *}$ : CVM and SBP data included in analysis. 


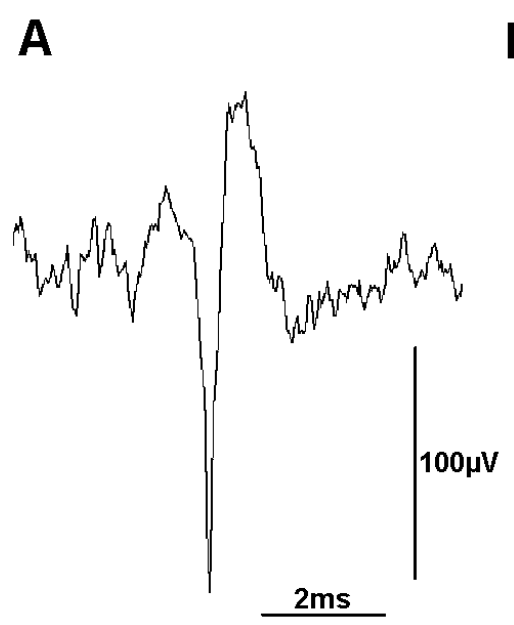

B

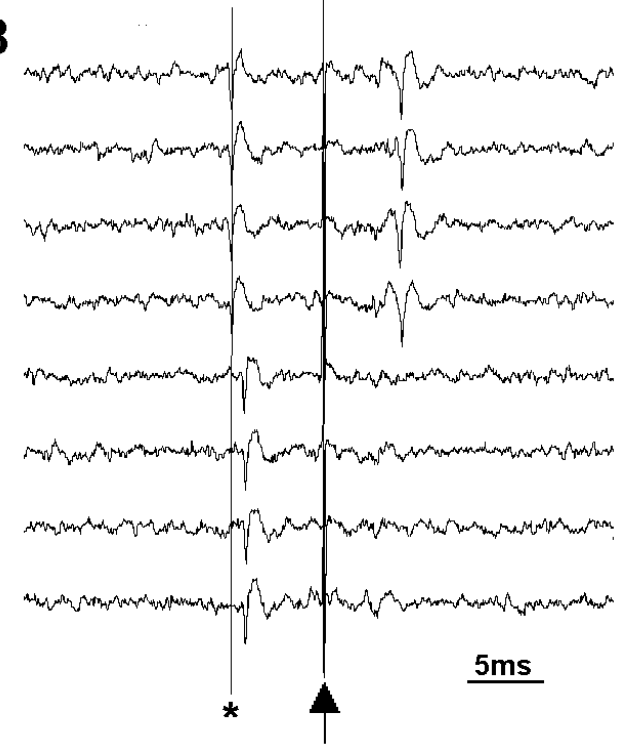

C
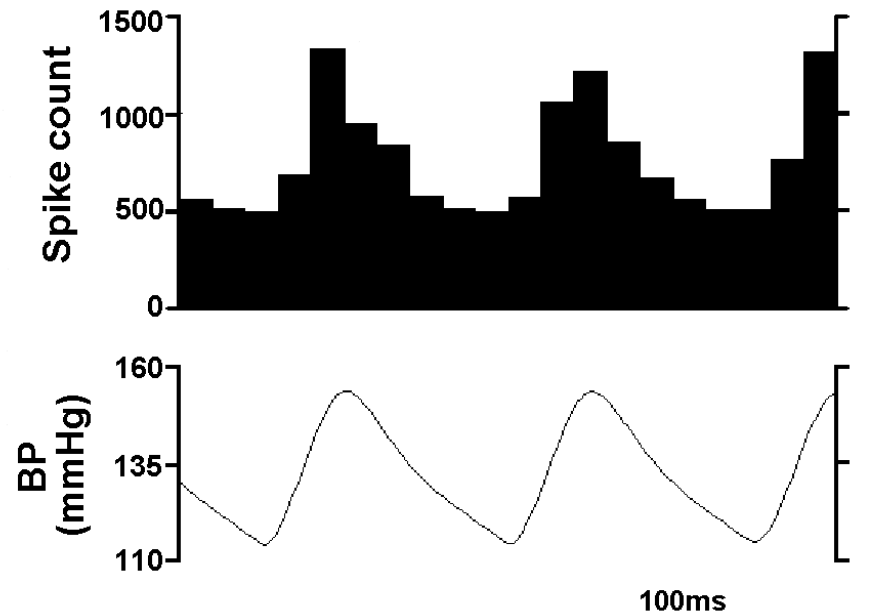

Figure 1 : Identification of a cardiac vagal motoneuron (CVM). A: Spontaneous discharge of a CVM. B: Collision test with a stimulus (artefact at vertical arrow) triggered $6 \mathrm{~ms}$ (top 4 traces) and $5 \mathrm{~ms}$ (bottom 4 traces) after a spontaneous spike (left side). The CVM gives a constant-latency, antidromic spike for a $6 \mathrm{~ms}$ delay but the depolarization is cancelled by the orthodromic spike when the delay is $5 \mathrm{~ms}$. Vertical line marked by star is traced at $6 \mathrm{~ms}$. C: Pulse-locked character of the unit (barosynchronicity): upper trace shows histogram of same CVM spontaneous activity (6703 cycles, 20ms bins), locked to arterial pulse pressure (lower trace). 
A
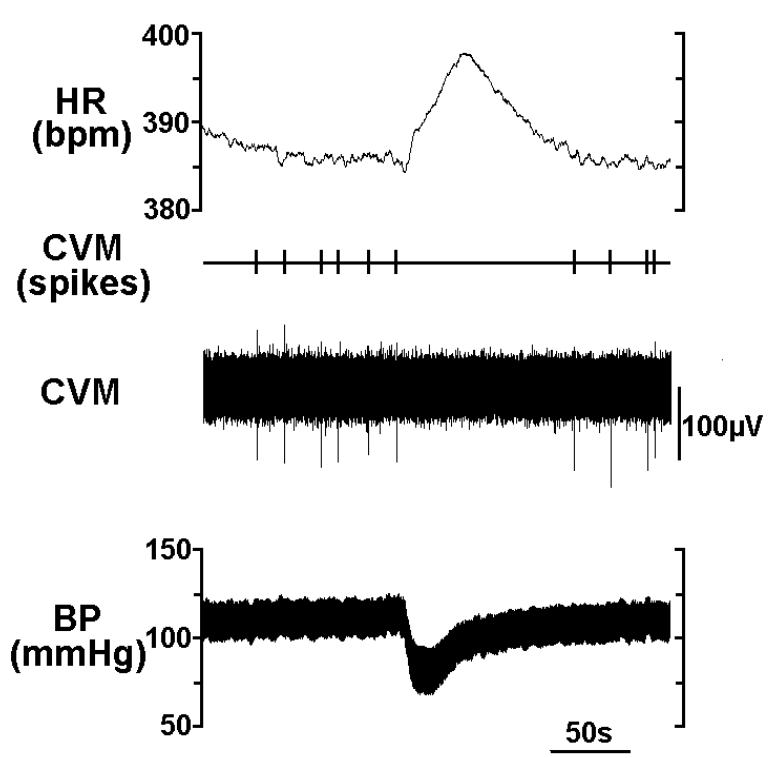

B
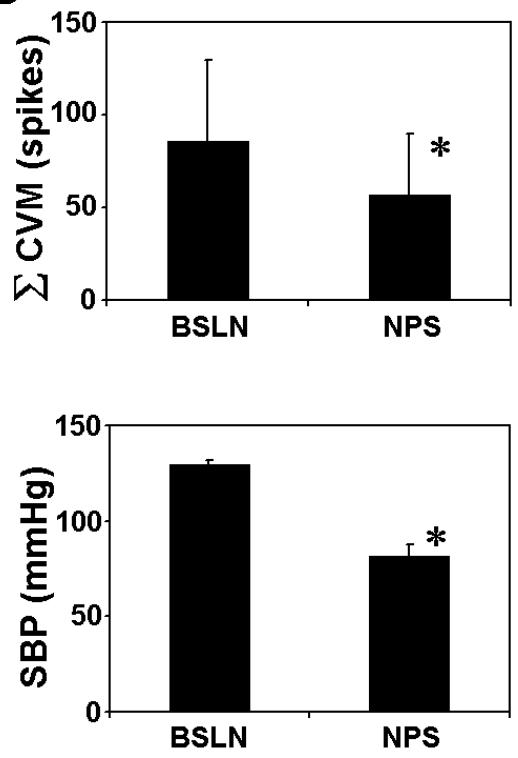

C

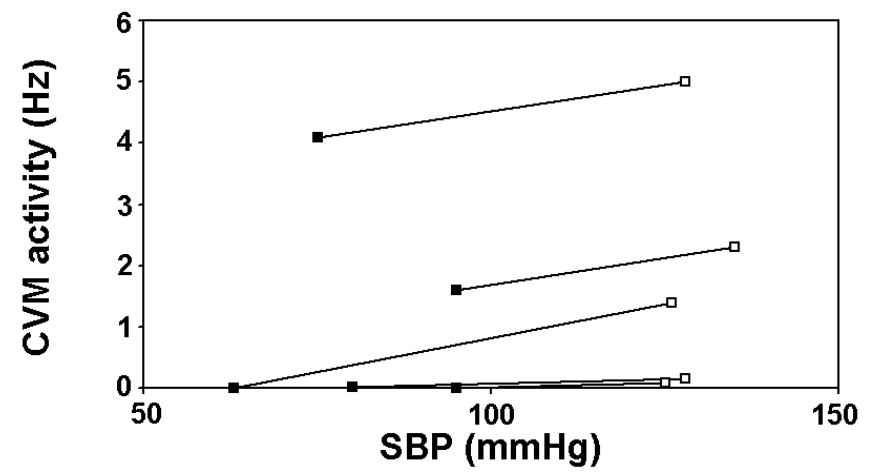

Figure 2 : A. CVM activity decreases during pressure fall evoked by nitroprusside. From bottom to top : BP, raw CVM signal, CVM detected spikes, HR (from EKG). B. CVM activity (top) decreases when nitroprusside is administered in 5 out of 5 rats. ${ }^{*}-p<0.05$ vs. Baseline for the considered variable. $(n=5$ cells in 5 rats). The total CVM spike counts was measured for 50 s before [baseline] and 50s immediately after injection [response]. C. Plot shows that nitroprusside decreases CVM activity and SBP in 5 out of 5 rats. Baseline: open squares; nitroprusside : closed squares. 

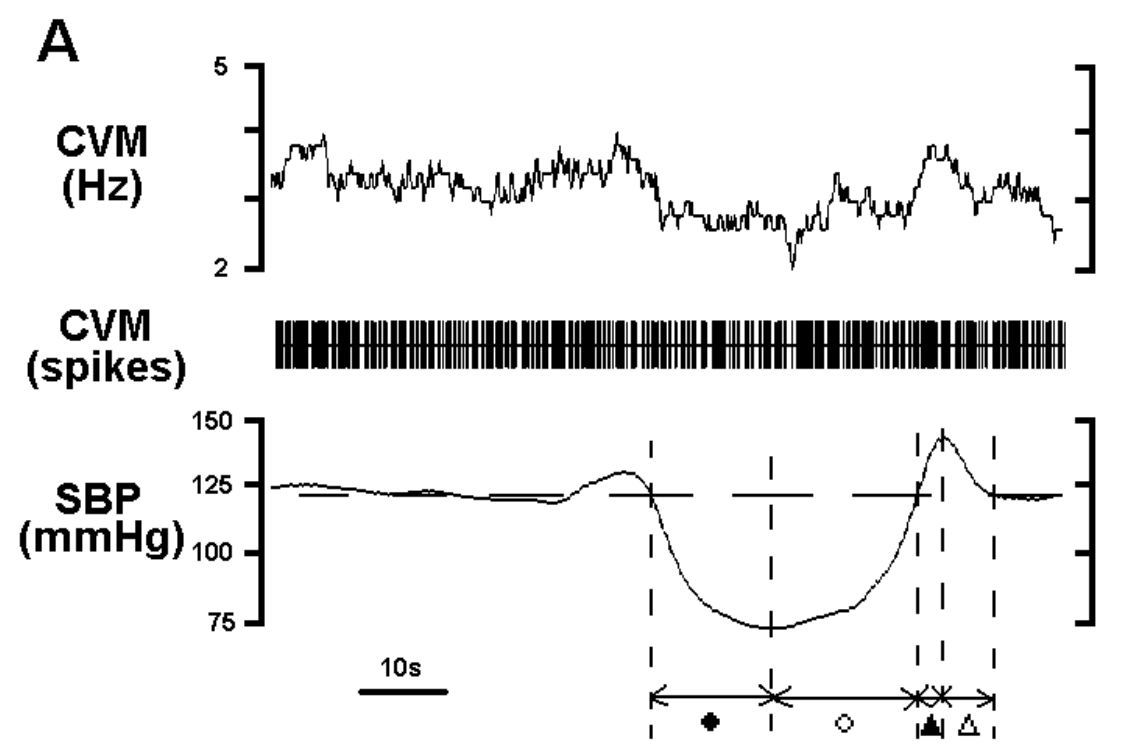

B

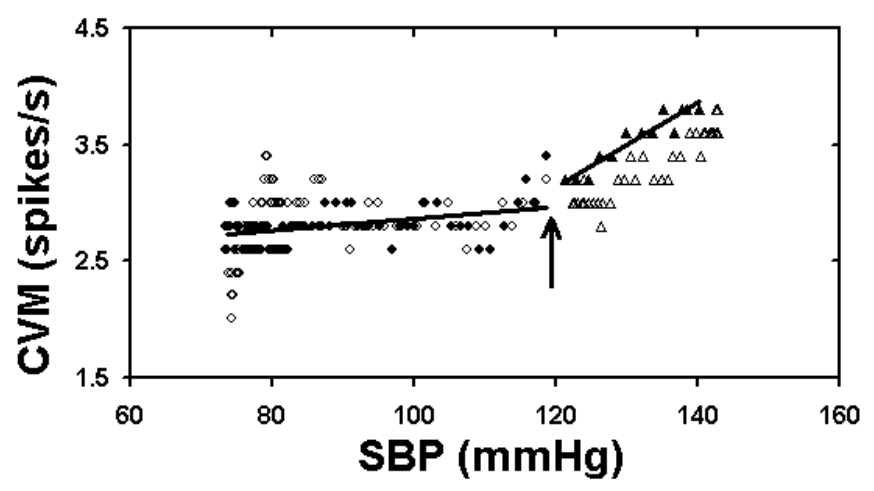

Figure 3 : A. Typical trace of CVM activity following nitroprusside-phenylephrine challenge. Phenylephrine was injected immediately following the nadir in pressure. Traces from bottom to top : SBP, CVM detected spikes, CVM (Hz). CVM activity and SBP averaged over 6 ventilatory cycles. Horizontal line corresponds to baseline SBP level. Vertical lines show pressure inflection points with corresponding symbols in figure B. B. Relation between the CVM activity and SBP for the sequence in A. Vertical arrow : baseline SBP and CVM activity. Closed circles = pressure fall after nitroprusside; open circles = pressure rising to baseline level. . losed triangles = pressure rise after phenylephrine; open triangles = pressure falling back to baseline. The solid lines are the regression lines relating the systolic pressure and the CVM activity during fall and rise in pressure (closed circles and triangles respectively; $R^{2}=0.1663, R^{2}=0.9069 ; n=1$ cell). Data may also fit a sigmoid $\left(R^{2}=0.63\right.$, not shown). 
A

HR

(bpm)

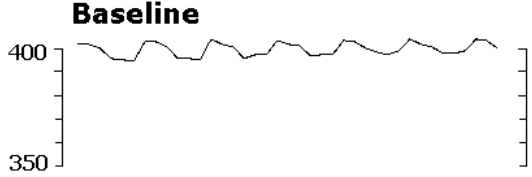

CVM

(spikes)

CVM

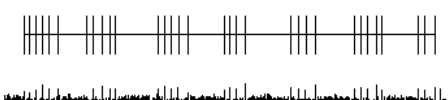

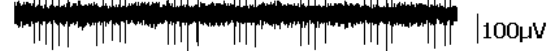

BP

${ }^{175}$ - 25 -

B

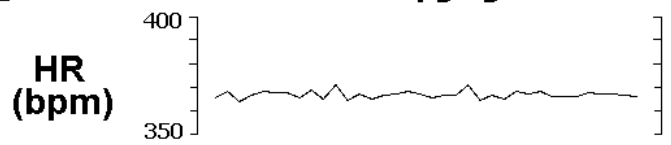

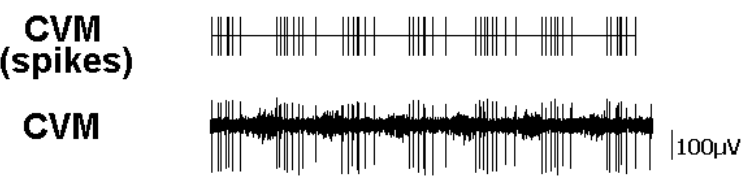

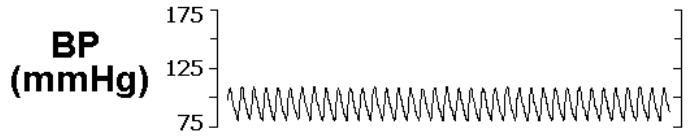

C

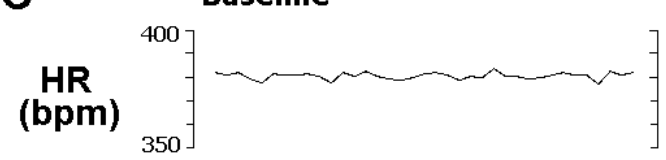

CVM

(spikes)

CVM

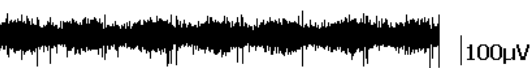

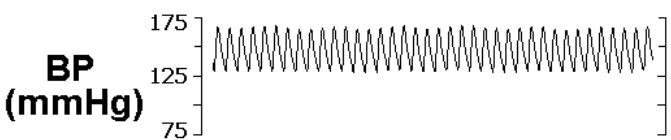

D

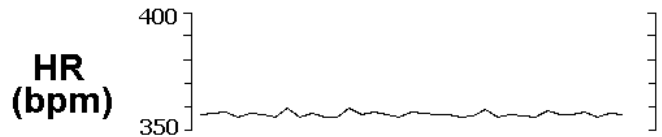

CVM

(spikes)

cVM

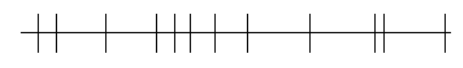

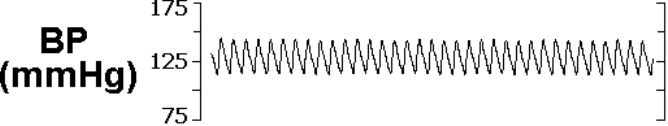

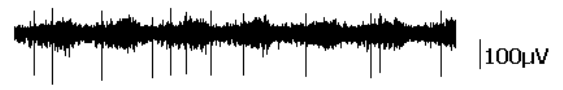

$1 \mathrm{~s}$

Figure 4 : Activation of CVM unit following clonidine $100 \mu$ g.kg ${ }^{-1}$ i.v. A,B : typical trace for one active unit at baseline. C,D : typical trace for one inactive unit at baseline. Traces from bottom to top : pulse pressure (BP, mm Hg), CVM activity (raw signal), CVM detected spikes, Heart rate (HR from EKG). 
A
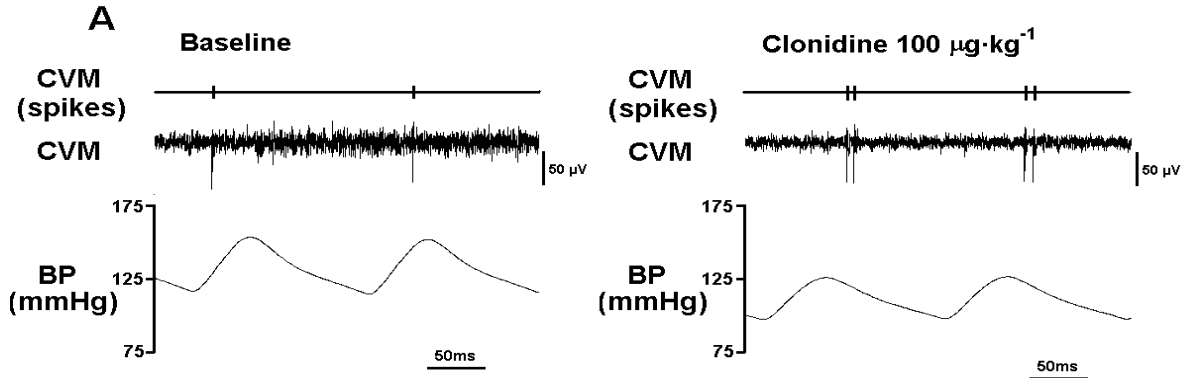

B
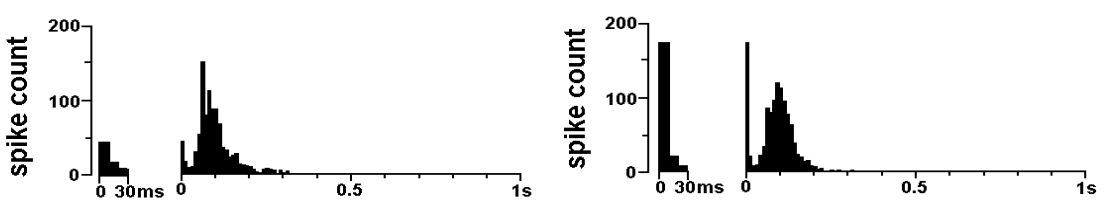

C

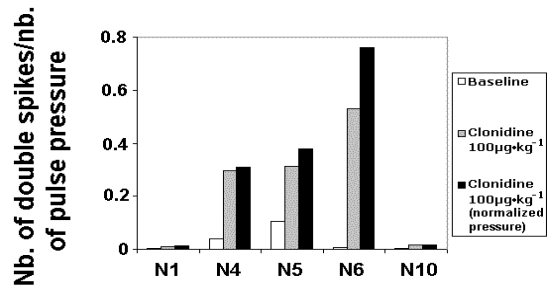

D

\begin{tabular}{|c|c|c|c|c|}
\hline Neurone & I & II & III & IV \\
\hline N1 & + & + & - & - \\
\hline N4 & + & - & 0 & 0 \\
\hline N5 & + & - & 0 & 0 \\
\hline N6 & + & - & - & 0 \\
\hline N10 & + & + & - & - \\
\hline
\end{tabular}

$\mathbf{E}$
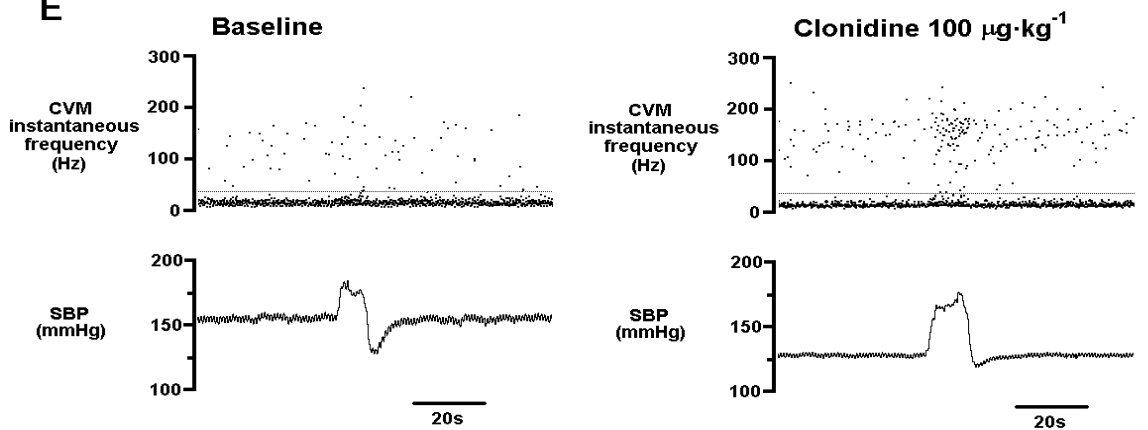

$\mathbf{F}$
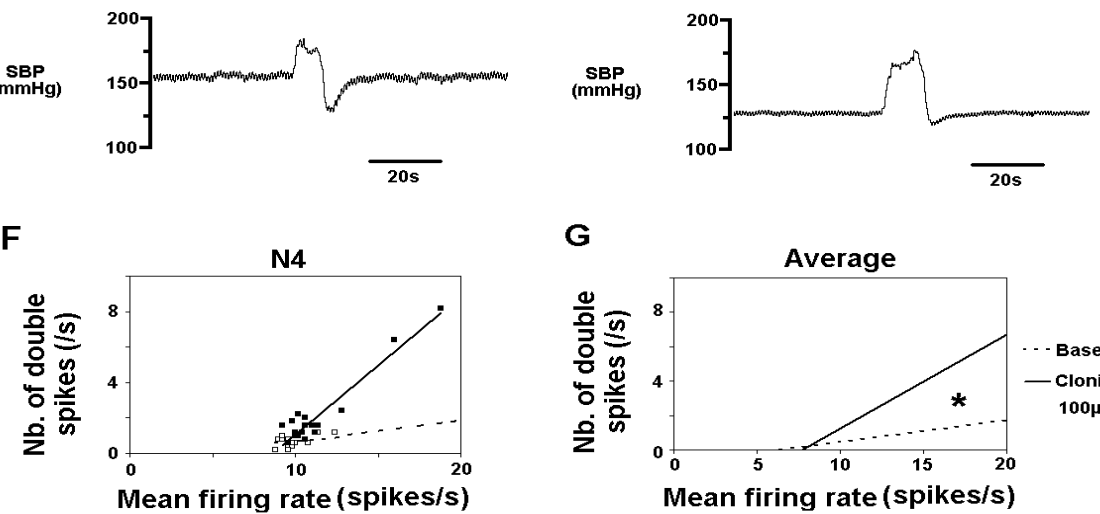

G

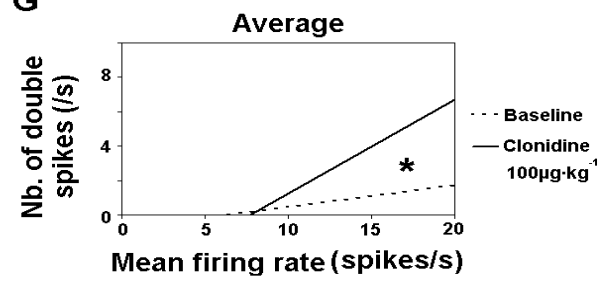

Figure 5 : Interspike intervals decrease following clonidine $100 \mu \mathrm{g} \cdot \mathrm{kg}^{-1}$ i.v ( $\mathrm{n}=5$ cells). A: Single spike (left) and double spikes ("doublet"; right : spikes with interspike interval $<30 \mathrm{~ms}$ ). Note the increase in double spikes after clonidine $100 \mu \mathrm{g} . \mathrm{kg}^{-1}$ under resting conditions. Traces (bottom to top) : pulse pressure (BP), raw CVM activity, detected CVM spikes. B: Interspike interval histogram of the same CVM in baseline (left) and clonidine $100 \mu \mathrm{gg} \cdot \mathrm{kg}^{-1}$ i.v. (right) conditions. Each histogram has at left a time-axis zoom (3x) of the $0-30 \mathrm{~ms}$ interval. Note the large increase of firing in the 0-30 ms interval Numbers of triggers (baseline, clonidine $100 \mu \mathrm{g} . \mathrm{kg}^{-1}$ ): 988, 1119; C: The number of double spikes per pulse pressure increases in 5 cells, especially when number of double spikes are normalized to baseline pressure. D: Changes in interspike interval (expressed as percentage of interspike interval : + for increasing, - for decreasing and 0 for unchanged) after clonidine $100 \mu \mathrm{g} . \mathrm{kg}^{-1}$. Interspike intervals are divided in four ranges : I : 0-30ms (double spikes); II : 30-600 ms; III : 600-1300 ms, IV, >1300 ms. Firing increases in the double spike interval range. By contrast, firing decreases in longer interspike interval ranges, indicative of tighter coupling between BP and CVM activity. E: The increase in double spike is even more prominent during pressure rise (balloon inflation) following clonidine $100 \mu \mathrm{g} . \mathrm{kg}^{-1}$ i.v. Left and Right : Typical traces at baseline and following clonidine $100 \mu \mathrm{g} . \mathrm{kg}^{-1}$ respectively. Traces (bottom to top) : CVM instantaneous firing frequency $(\mathrm{Hz})$, pulse pressure $(\mathrm{BP}, \mathrm{mm} \mathrm{Hg})$. Horizontal line shows frequency corresponding to $30 \mathrm{~ms}$ interspike interval. Dots above horizontal line correspond to double spikes. $\mathrm{F}$ : number of double spikes vs. mean firing rate for 1 cell before (open symbols and dotted regression line) and after clonidine $100 \mu \mathrm{g}_{\mathrm{kg}}{ }^{-1} \mathrm{i}$ i.v. (closed symbols and solid regression line). $G$ : aggregated data for 5 cells in 5 different rats * $: p=0.043$ for slopes. 
A Baseline

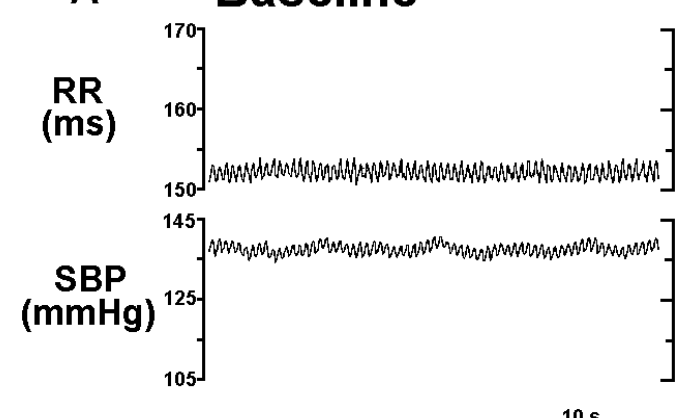

B Clonidine 100 $\mu \mathrm{g} \cdot \mathrm{kg}^{-1}$

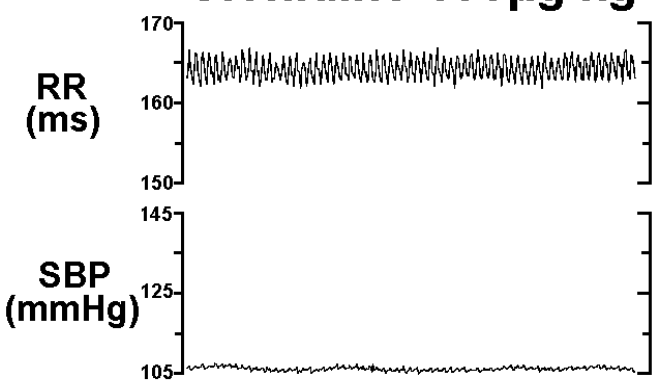

$10 \mathrm{~s}$

Figure 6. Raw traces of RR interval (top) and systolic blood pressure (SBP, bottom) in one rat during baseline (A) and clonidine $100 \mu g . k g-1$ i.v. (B) 
A Baseline

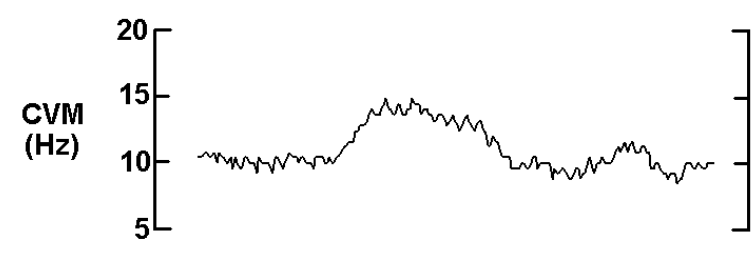

CVM (spikes)
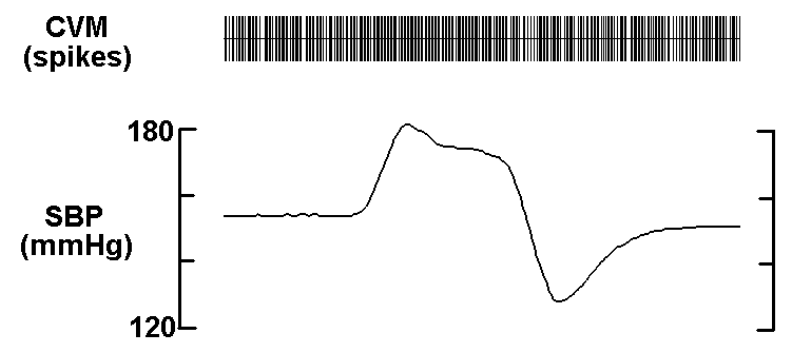

$10 \mathrm{~s}$

\section{C}

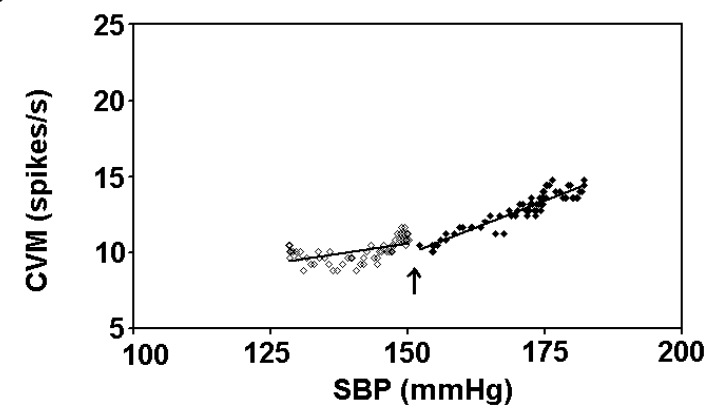

B Clonidine $100 \mu \mathrm{g} \cdot \mathrm{kg}^{-1}$
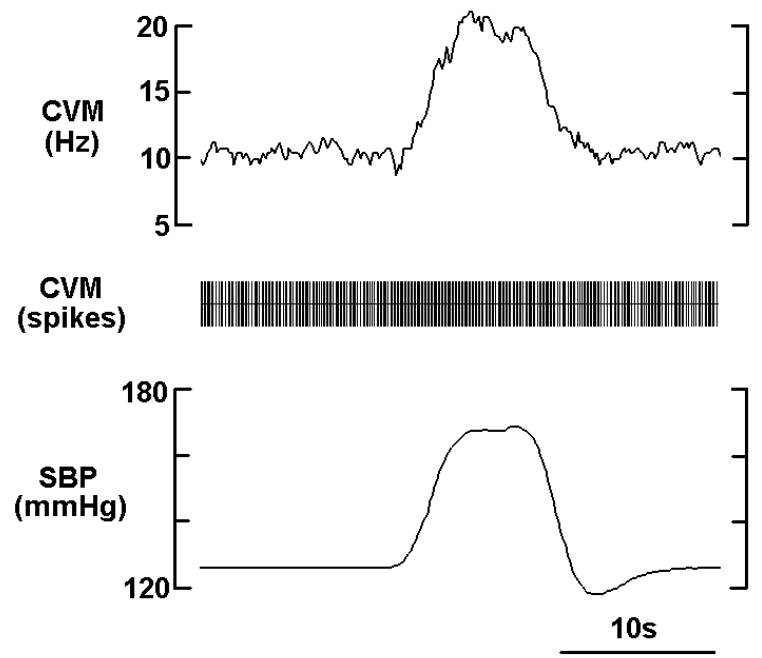

D

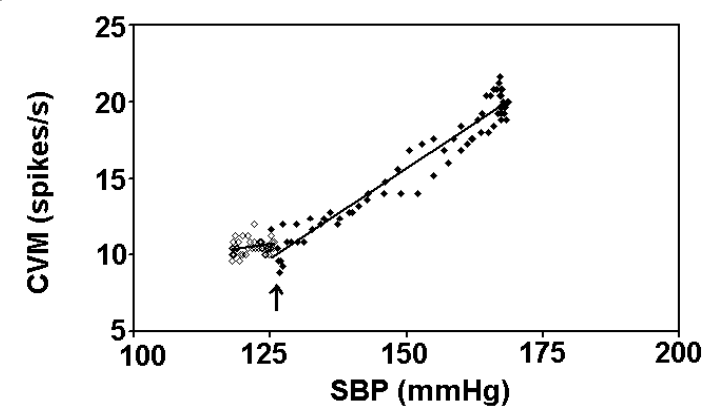

Figure 7 : Typical trace of CVM activity following balloon inflation (top) in baseline (A) and clonidine $100 \mu$ g.kg ${ }^{-1}$ i.v. (B) conditions. Traces from bottom to top : SBP, CVM detected spikes, CVM (Hz). CVM activity and SBP averaged over 3 ventilatory cycles. Scatter plot of mean firing rate vs. mean systolic blood pressure for a CVM during balloon inflation in baseline (C) and clonidine $100 \mu \mathrm{g} . \mathrm{kg}^{-1}$ i.v. (D) conditions. The linear regression lines for the relations are shown $\left(R^{2}=0.33\right.$ and 0.07 for reduction in pressure for baseline and clonidine $100 . \mu \mathrm{g} . \mathrm{kg}-1$ respectively; $R^{2}=0.87$ and 0.95 for rises in pressure for baseline and clonidine $100 \mu \mathrm{g} \cdot \mathrm{kg}^{-1}$ respectively). arrow : resting SBP and CVM activity. 
A

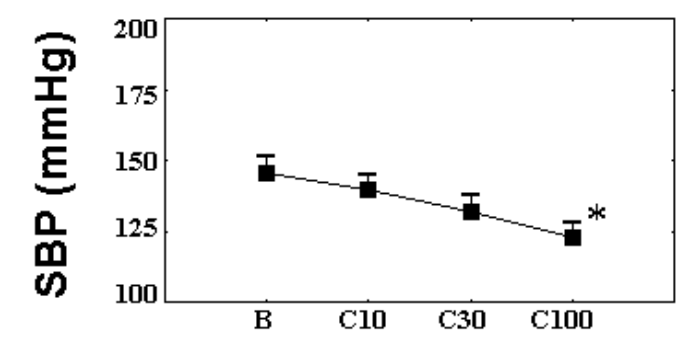

C

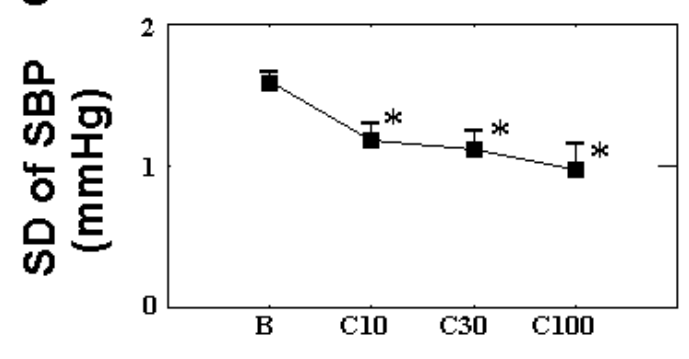

B

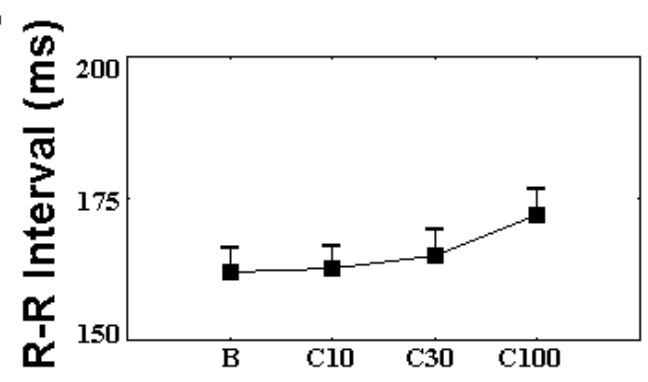

D

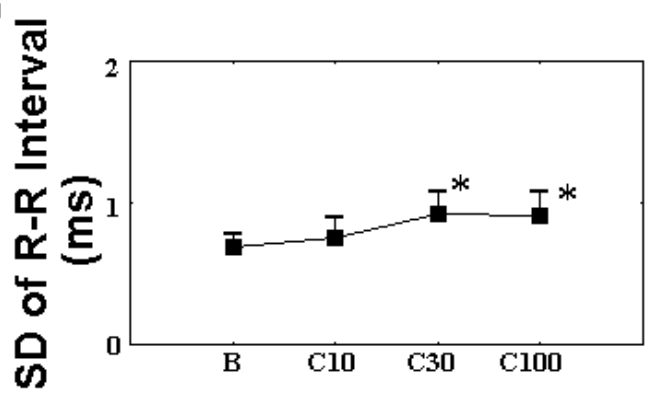

E

$F$
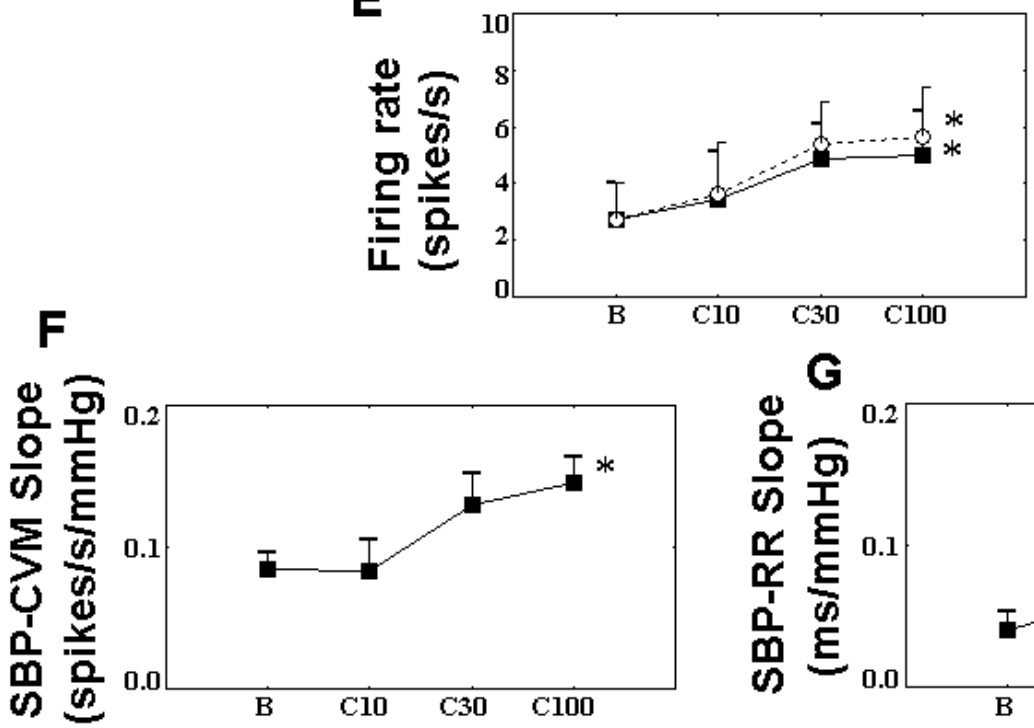

G

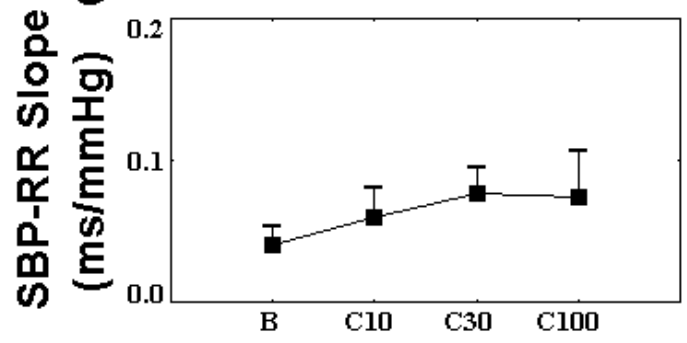

B : baseline

$\mathrm{C} 10,30,100$ : clonidine $10,30,100 \mu \mathrm{g}+\mathrm{kg}^{-1}$

Figure 8 : Effect of cumulative doses of i.v. clonidine on circulatory variables, unit activity and cardiac baroreflex analysed at CVM and heart levels ( $n=8$ cells in 8 different rats). A: Systolic blood pressure (SBP). B: R-R interval. C: Standard deviation of SBP. D: Standard deviation of R-R interval. E: Closed squares: mean firing rate. Open circles: normalized firing rate : mean firing rate multiplied by the ratio between SBP at baseline and current SBP. F: slope of SBP-CVM activity (cardiac baroreflex analysed at CVM level) during balloon inflation. Note the increased sensitivity. G: slope of SBP-R-R interval (cardiac baroreflex analyzed at heart level) during balloon inflation. B : Baseline; C10 : clonidine $10 \mu \mathrm{g} . \mathrm{kg}^{-1}$ i.v; C30 : clonidine $30 \mu \mathrm{g} . \mathrm{kg}^{-1}$ i.v., C100 : clonidine $100 \mu \mathrm{g} . \mathrm{kg}^{-1}$ i.v. $^{*}:$ p<0.05 vs. baseline for the considered variable. 